\title{
DUCTILE FRACTURE CRITERION FOR SPECIMENS WITH NOTCHES MADE OF ALUMINIUM ALLOY EN-AW 2024
}

\author{
Łukasz Derpeński, Andrzej Seweryn \\ Bialystok University of Technology, Faculty of Mechanical Engineering, Poland \\ e-mail: l.derpenski@pb.edu.pl; a.seweryn@pb.edu.pl
}

\begin{abstract}
The paper presents the experimental verification of the most frequently used ductile fracture criteria based on authors own experimental results and numerical calculations. Attention is drawn to the large discrepancy of results of fracture prediction and experimental data for six considered criteria. Based on own results, a new ductile fracture criterion for notched specimens is proposed. In the criterion, it is assumed that fracture initiation occurs when the maximum normal stress reaches a critical value depending on the maximum value of plastic shear strain.
\end{abstract}

Keywords: numerical analysis, fracture of specimen with notches, ductile fracture criterion

\section{Introduction}

Exploration of the phenomena associated with ductile fracture of materials continues over 50 years. Attempts to describe ductile failure are carried out at two scales. The microscopic, where fracture is a result of complex physical processes (Thomason, 1990; Öchsner et al., 2001; Bandsta and Koss, 2004), and the macroscopic where fracture is assumed to be caused by state variables which are components of the stress and strain tensor and their variation during load (Bao, 2001, 2005). Starting from the work by McClintock (1968), continuously more and more new fracture criteria are created showing how important the problem is. Yanshan et al. (2012) proposed a new ductile fracture criterion to model fracture behavior of sheet metals for nucleation, growth and shear coalescence of voids during plastic deformation. Komori (2005) showed the effect of various ductile fracture criteria on crack initiation and propagation during shearing and tensile tests. Yanshan and Hoon (2013) presented evaluation of ductile fracture criteria in a general three-dimensional stress state of stress triaxiality, the Lode parameter and the equivalent plastic strain to fracture. Ma et al. (2015) presented damage evaluation in tube spinnability test using ductile fracture criteria.

This study aims to select appropriate ductile fracture criteria (DFCs) in terms of damage limits which have been obtained by mechanical tests, to accurately predict the forming limit and damage evolution in the tube spinability test. Chena et al. (2015) calculated the sheet metal forming limit prediction based on the general plastic work criterion and some ductile fracture criteria. There is a continuing need to develop new and verify the existing criteria. Most of them are due to the used material parameters and components of the stress or strain tensor which is very complicated and often difficult to verify. Therefore, it is necessary to create a fracture criterion, which is sufficiently simple and not containing many difficult to determine parameters in order to predict fracture of material. Based on the authors' own research results (Derpeński, Seweryn, 2011, Derpeński, Seweryn, 2013), verification of selected ductile fracture criteria and formulation of authors' own stress fracture criterion, in which the critical stress value depends on the value of the maximum plastic shear strain, is presented. 


\section{Experimental tests}

The main stage of experimental tests is the analysis of fracture in specimens with circumferential notches (Fig. 1) whose dimensions have been selected so that different states of stress could be obtained in the plane of notch symmetry (Derpeński and Seweryn, 2011). The dimensions of the specimens selected for the analysis are listed in Table 1.

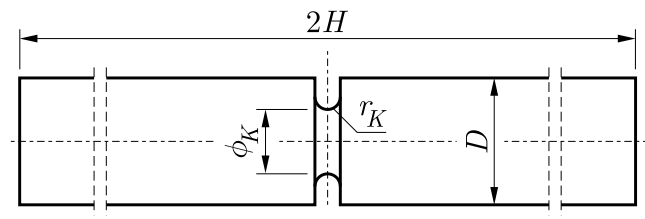

Fig. 1. A cylindrical notched specimen with radius $r_{k}$ and diameter $\phi_{k}$

Table 1. Dimensions of specimens for experimental tests

\begin{tabular}{|c|c|c|c|c|}
\hline Shape & $r_{k}[\mathrm{~mm}]$ & $\phi_{k}[\mathrm{~mm}]$ & $2 H[\mathrm{~mm}]$ & $D[\mathrm{~mm}]$ \\
\hline \hline I & $0.3 ; 0.5 ; 1.0 ; 2.0 ; 4.0 ; 8.0 ; 15 ; 30$ & 8.0 & & \multirow{2}{*}{120} \\
\cline { 1 - 3 } II & $0.3 ; 0.5 ; 1.0 ; 2.0 ; 4.0 ; 8.0 ; 15 ; 30$ & 7.0 & \\
III & $0.3 ; 0.5 ; 1.0 ; 2.0 ; 4.0 ; 8.0 ; 15 ; 30$ & 6.0 & & \\
\hline
\end{tabular}

$r_{k}$ - notch radius; $\phi_{k}$ - specimen diameter at the root of the notch;

$2 H$ - height of the specimen; $D$ - diameter of the specimen

The specimens have been extended by applying forced displacement controlled by means of an extensometer with its measurement base of $25 \mathrm{~mm}$ (Fig. 2).

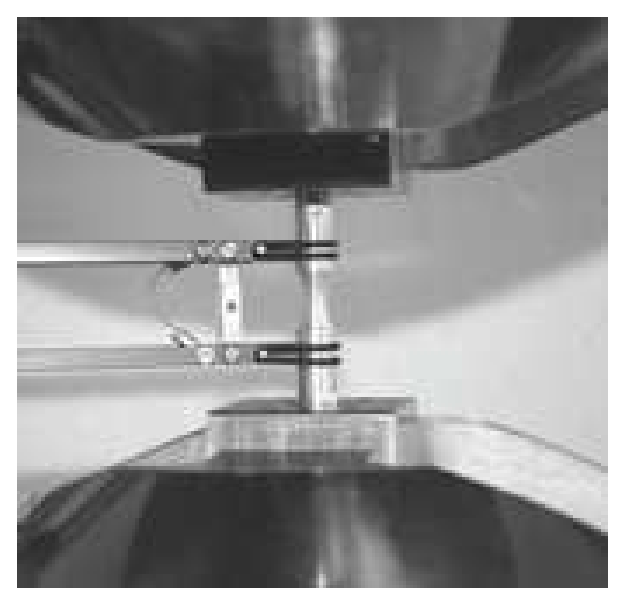

Fig. 2. Round notched specimen with an axial extensometer

As a result of the conducted tests, the authors recorded the relations between the tensile force and the elongation of the measurement base $\left(l_{0}=25 \mathrm{~mm}\right)$ for each notch, particularly the maximum (critical) displacement of the measurement base $u_{c}$ and the critical force $F_{c}$ causing fracture initiation in the specimen. The moment of fracture initiation indicates a significant decrease in the force value in the force-displacement graph. Table 2 and 3 present the results of tests on specimens with notches in different shapes as well as the averaged values of four specimens: the maximum displacement $\bar{u}_{c}$ and the critical force $\bar{F}_{c}$.

Figure 3 presents the dependence of the constant diameter at the root of the notch $\phi_{k}$. The curves shown in the graphs are the average values of four repetitions conducted for each type of the specimen. 
Table 2. Results of fracture tests on notched specimens

\begin{tabular}{|c|c|c|c|c|c|c|c|c|c|c|c|c|}
\hline $\begin{array}{l}\text { No. of } \\
\text { spec. }\end{array}$ & $\begin{array}{c}r_{k} \\
{[\mathrm{~mm}]}\end{array}$ & $\begin{array}{c}\phi_{k} \\
{[\mathrm{~mm}]}\end{array}$ & \multicolumn{4}{|c|}{$u_{c}[\mathrm{~mm}]$} & $\begin{array}{c}\bar{u}_{c} \\
{[\mathrm{~mm}]}\end{array}$ & \multicolumn{4}{|c|}{$F_{c}[\mathrm{kN}]$} & $\begin{array}{c}\bar{F}_{c} \\
{[\mathrm{kN}]}\end{array}$ \\
\hline 1 & & 6 & 246 & 0 . & .268 & .248 & 0.249 & 19 & 19 & 19.23 & 18.81 & 9.1 \\
\hline 2 & 0.3 & 7 & 96 & & & & 384 & & 23 & 4 & 30 & 3.58 \\
\hline 3 & & 8 & 588 & 0.552 & 0.566 & 618 & 0.581 & 26.00 & 26.48 & 27.04 & 27.08 & 26.65 \\
\hline 4 & & 6 & 350 & 0.340 & 0.342 & .350 & 0.345 & & 19.56 & 20.06 & 19.82 & 19.83 \\
\hline 5 & 0.5 & 7 & 424 & 0.476 & 0.468 & 0.456 & 0.456 & 23.61 & 23.71 & 23.64 & 23.91 & 23.72 \\
\hline 6 & & 8 & 2 & 0.7 & 0.698 & 18 & 0.726 & 2 & & 27.47 & & 27.51 \\
\hline 7 & & 6 & 2 & 0.466 & 0.492 & 8 & .483 & 19 & 19 & 20.00 & 19.72 & 19.70 \\
\hline 8 & 1.0 & 7 & 0.600 & 0.652 & 0.632 & 0.676 & 0.640 & 23.61 & 23.79 & 23.82 & 25.17 & 24.10 \\
\hline 9 & & 8 & 6 & 1.2 & 1.018 & 1.058 & 1.071 & 28 & 28 & 28.42 & 2 & 28.63 \\
\hline 10 & & 6 & & 0.6 & .668 & & 0.667 & & 18 & 18.42 & 0 & 18.22 \\
\hline 11 & 2.0 & 7 & 0 & 1.0 & 6 & 16 & 1.024 & & 24.06 & 24.29 & & 24.12 \\
\hline 12 & & 8 & 1.712 & 1.692 & 1.552 & 1.564 & 1.630 & 29.55 & 29 & 29.67 & 29.26 & 29.47 \\
\hline$\overline{13}$ & & 6 & 0 & 0.7 & 0.714 & 4 & 0.731 & $\overline{16}$ & 16 . & 15.97 & 16 & 16.27 \\
\hline 14 & 4.0 & 7 & & 1. & 8 & & 1.103 & & 22 & 21.68 & & 22.26 \\
\hline 15 & & 8 & 44 & 1.980 & 2.036 & 24 & 1.996 & 28 & 29.00 & 28.58 & 28.46 & 28.51 \\
\hline 16 & & 6 & 1.092 & 1.142 & 1.094 & 1.108 & 1.109 & 15 & 15.35 & 15.37 & 14.78 & 15.17 \\
\hline 17 & 8.0 & 7 & 1.280 & 1.2 & 1.220 & 1.1 & 1.227 & 20.33 & 20.36 & 20.51 & 19.30 & 20.13 \\
\hline 18 & & 8 & 2.032 & 2.1 & 2.056 & 2.048 & 2.061 & & 27 & 27.20 & 27.34 & 27.30 \\
\hline 19 & & 6 & & 1.600 & 1.552 & 1.572 & 1.574 & & 14.39 & 14.78 & 14.12 & 14.47 \\
\hline 20 & 15.0 & 7 & 1. & 1.705 & 1.625 & 1.705 & 1.705 & 19.911 & 19.64 & 19.30 & 19.61 & 19.61 \\
\hline 21 & & 8 & 2 & 2.140 & 2.155 & 2.145 & 2.141 & 25.90 & 25.65 & 26.30 & 25.94 & 25.95 \\
\hline 22 & & 6 & 2.160 & 2.1 & 2.076 & 2.072 & 2.103 & & 13 & 13.72 & 13.67 & 13.70 \\
\hline 23 & 30.0 & 7 & 2.295 & 2.305 & 2.265 & 2.295 & 2.290 & & 19.28 & 19.23 & 19.25 & 19.25 \\
\hline 24 & & 8 & 2.632 & 2.605 & 2.623 & 2.620 & 2.620 & 25.26 & 25.03 & 25.04 & 25.21 & 25.14 \\
\hline
\end{tabular}

Additionally, the linear strain at the notch root for whole specimens at the fracture initiation moment (Bringdman, 1964) has been calculated.

Table 3. Values of linear strain at the fracture initiation moment

\begin{tabular}{|c|c|c|c|c|c|c|c|c|c|c|c|c|}
\hline$r_{k}$ & \multicolumn{3}{|c|}{0.3} & \multicolumn{3}{c|}{0.5} & \multicolumn{3}{c|}{1} & \multicolumn{3}{|c|}{2} \\
\hline$d_{0}$ & 6 & 7 & 8 & 6 & 7 & 8 & 6 & 7 & 8 & 6 & 7 & 8 \\
\hline \hline$d_{f}$ & 5.312 & 6.084 & 7.042 & 5.306 & 6.236 & 7.139 & 5.382 & 6.325 & 7.199 & 5.519 & 6.286 & 7.131 \\
\hline$\varepsilon_{f}$ & 0.244 & 0.280 & 0.255 & 0.246 & 0.231 & 0.228 & 0.217 & 0.203 & 0.211 & 0.167 & 0.215 & 0.230 \\
\hline$r_{k}$ & \multicolumn{3}{|c|}{4} & \multicolumn{3}{|c|}{8} & \multicolumn{3}{c|}{15} & \multicolumn{3}{|c|}{30} \\
\hline$d_{0}$ & 6 & 7 & 8 & 6 & 7 & 8 & 6 & 7 & 8 & 6 & 7 & 8 \\
\hline \hline$d_{f}$ & 5.657 & 6.487 & 7.199 & 5.604 & 6.580 & 7.437 & 5.598 & 6.548 & 7.464 & 5.566 & 6.501 & 7.433 \\
\hline$\varepsilon_{f}$ & 0.118 & 0.152 & 0.211 & 0.137 & 0.124 & 0.146 & 0.139 & 0.133 & 0.139 & 0.150 & 0.148 & 0.147 \\
\hline
\end{tabular}

The authors paid special attention to the influence of radius $r_{k}$ and diameter $\phi_{k}$ at the root of the notch on the course of $F-u$ graph as well as values of $u_{c}$ and $F_{c}$. The critical displacement $u_{c}$ increases along with an increase in the radius $r_{k}$, and the course of $F$ - $u$ relation becomes less dramatic. In most cases, an increase in the radius $r_{k}$ resulted in a decrease in the critical force $F_{c}$. An increase in the diameter $\phi_{k}$ at the root of the notch, with a constant radius $r_{k}$, increased the loading which resulted in the appearance of plastic strain in the specimen and also increased the critical force $F_{c}$ as well as critical displacement of the measurement base $u_{c}$. 
(a)

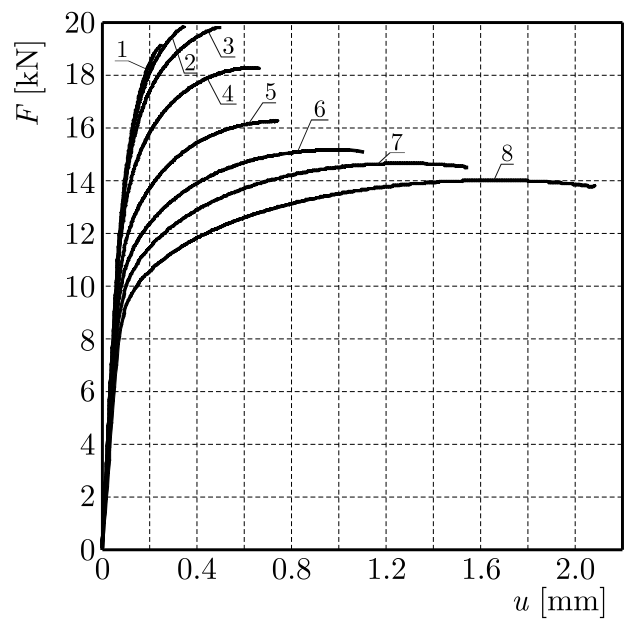

(c)

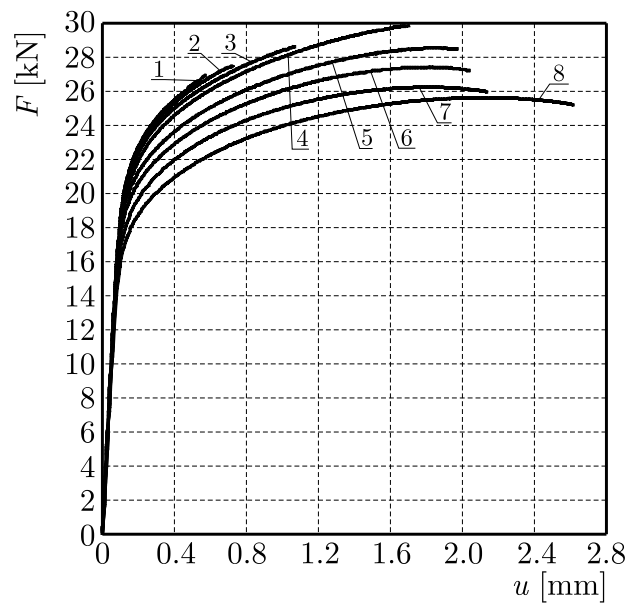

(b)

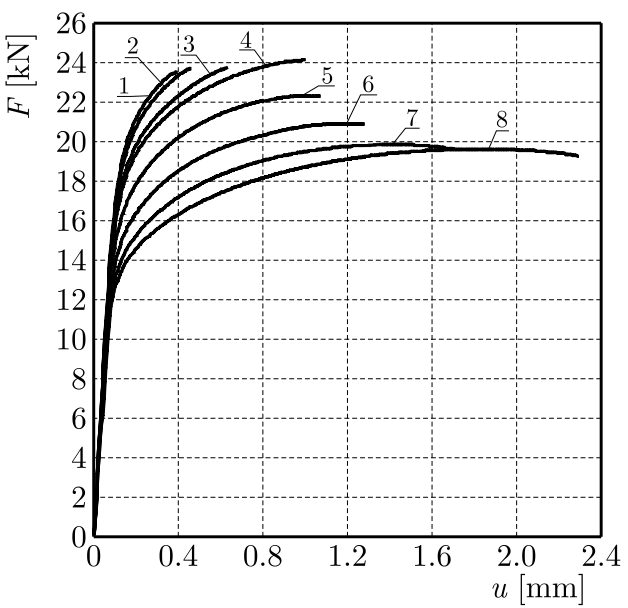

Fig. 3. Comparison of the force-displacement dependence in the notched specimen: (a) $\phi_{k}=6 \mathrm{~mm}$, (b) $\phi_{k}=7 \mathrm{~mm}$, (c) $\phi_{k}=8 \mathrm{~mm}$

\section{Numerical research}

The stress and strain distribution in the specimens with notches made of aluminum alloy EN-AW 2024 have been defined according to MSC.MARC software (Derpeński and Seweryn, 2013). The calculations allowed for the axial as well as notch symmetry. Four-nodal isoparametric finite elements have been applied. Geometric and material non-linearity has been taken into consideration. For all the samples undertaken, in the plane symetry of notches, the same division of finished elements has been used.

For all specimens, in the surface of notch symmetry, identical finite elements have been applied. The following boundary conditions are applied in calculations (Fig. 5): the axial symmetry of the geometric model ( $u_{r}=0$ on the specimen axis), notch symmetry $\left(u_{z}=0\right.$ on the surface of the notch symmetry). The load of the numerical calculation has been realized with the help of the set displacement uc of the measurement base, which have been calculated for each specimen type directly as a result of the experiment.

In order to describe the dependence between the stress $\sigma_{z z}$ and the axial strain $\varepsilon_{z z}$ in the specimens, an elastic and plastic material model with isotropic hardening has been applied. The Huber-von Misses plasticity yield criterion has been applied. The curve of material hardening has been approximated with a broken line (straight segments). The shape of the hardening curve up to necking has been determined directly from the experiment. The remaining curve range has been defined with a repeated numerical calculations, taking the necking effect into consideration 


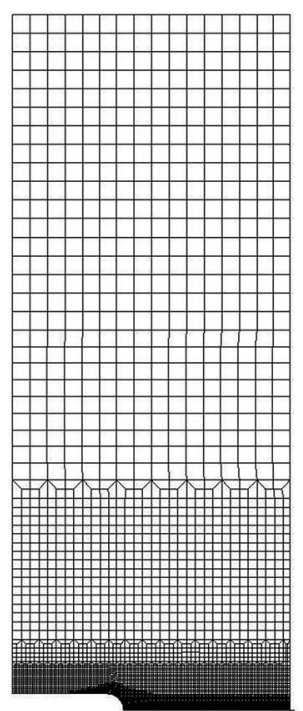

$r_{K}=0.3 \mathrm{~mm}$

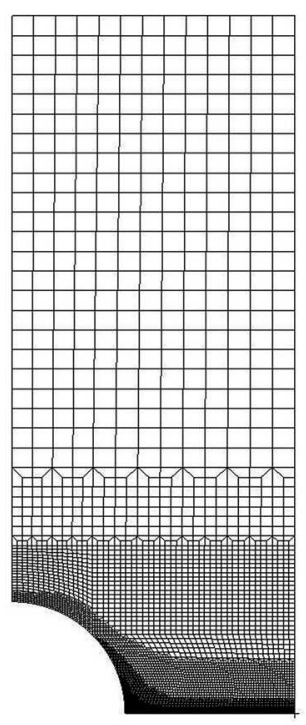

$r_{K}=2.0 \mathrm{~mm}$

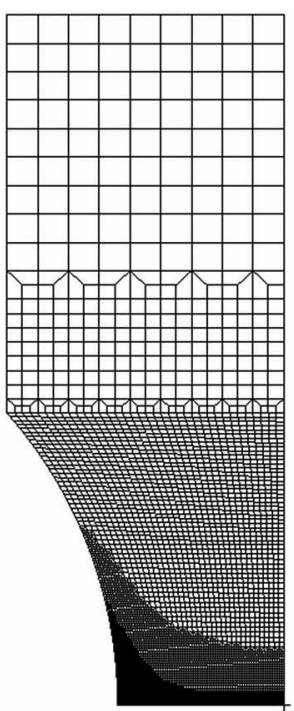

$r_{K}=8.0 \mathrm{~mm}$

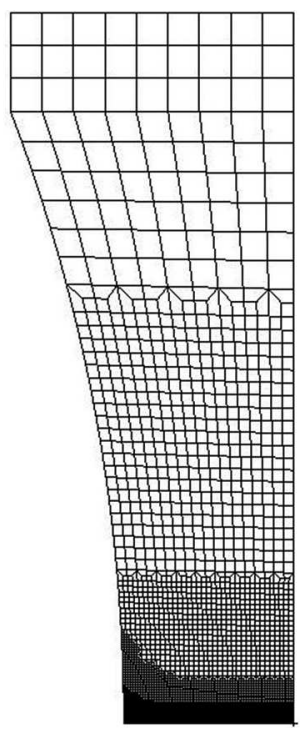

$r_{K}=30.0 \mathrm{~mm}$

Fig. 4. Finite element mesh for specimens with diameter $\phi_{k}=6 \mathrm{~mm}$

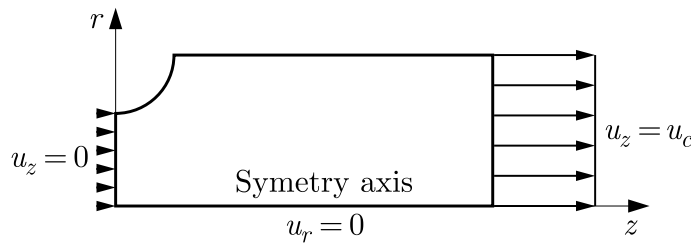

Fig. 5. Boundary conditions and loads used in numerical calculation

up to the moment when the shape of the curve force-displacement $(F-u)$ from the numerical calculations was close to the value of the curve force-displacement from experimental research. Figure 6 shows the actual hardening curves $\sigma-\varepsilon$ received in the complete range for aluminum alloys.

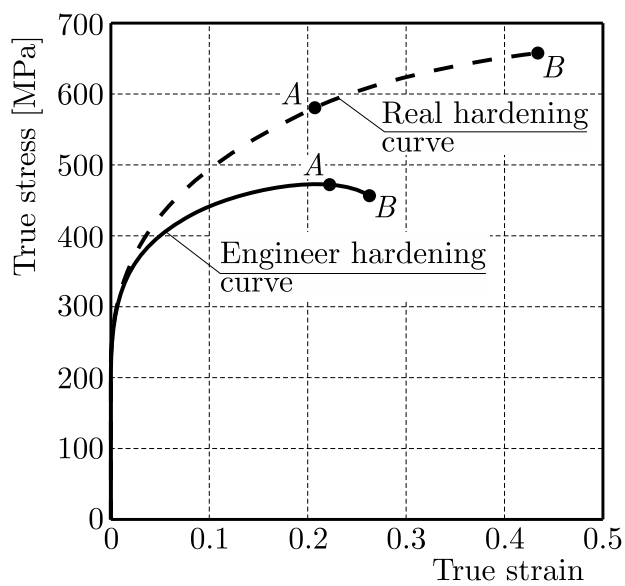

\begin{tabular}{|c|c|c|c|}
\hline$E[\mathrm{GPa}]$ & $\nu$ & $R_{c}[\mathrm{MPa}]$ & $R_{u}[\mathrm{MPa}]$ \\
\hline 69.65 & 0.34 & 260.02 & 658.34 \\
\hline
\end{tabular}

$A$ - point of necking

$B$ - point of failure

Fig. 6. Stress-strain curve for aluminum alloy EN-AW 2024

Based on numerical results (Derpeński and Seweryn, 2013), it is found that the distribution of $\sigma_{1}$ depends on the size of $r_{k}$. For notches with larger radii $\left(r_{k} \geqslant 2 \mathrm{~mm}\right)$, these values are located on the axis of the specimen. In the case of notches with smaller radii $\left(r_{k}<2 \mathrm{~mm}\right)$, the maximum value of $\sigma_{1}$ is found near to the notch root. 
It should be noted that in the case of specimens with $r_{k}=0.3$ and $r_{k}=0.5 \mathrm{~mm}$, the plasticization has not taken place in the entire cross-section of the symmetry plane of the notch. In specimens with $r_{k}=1$ and $r_{k}=2 \mathrm{~mm}$, at the moment of fracture initiation, complete plasticization the cross-section in the plane symmetry of the specimen occured. Although, the difference in values of stresses at the notch root and at the axis are very wide. Almost equal plasticization takes place in the whole cross-section at the remaining specimens with notches $\left(r_{k}=4,8,15,30 \mathrm{~mm}\right)$. From the experimental research (Derpeński and Seweryn, 2011), it is known that the surface of the fracture depends on the notch radius, and partially or fully cover with the plane of symmetry of the notch. Therefore, the distributions of stress and strain fields are subjected to detailed analysis in the plane of symmetry of the notch where the fracture initiates. Figures 7-9 present selected distributions: stress and plastic strain tensor components, the maximal plastic transverse strain at the critical load. The values of $r$ (distance from the axis of specimen) are normalized by $\phi_{k}$. In Table 4 for EN-AW 2024 aluminum alloy, values of the stress and plastic strain tensor components at the notch root and at the point of the maximum normal stress at the moment of fracture initiation are given.
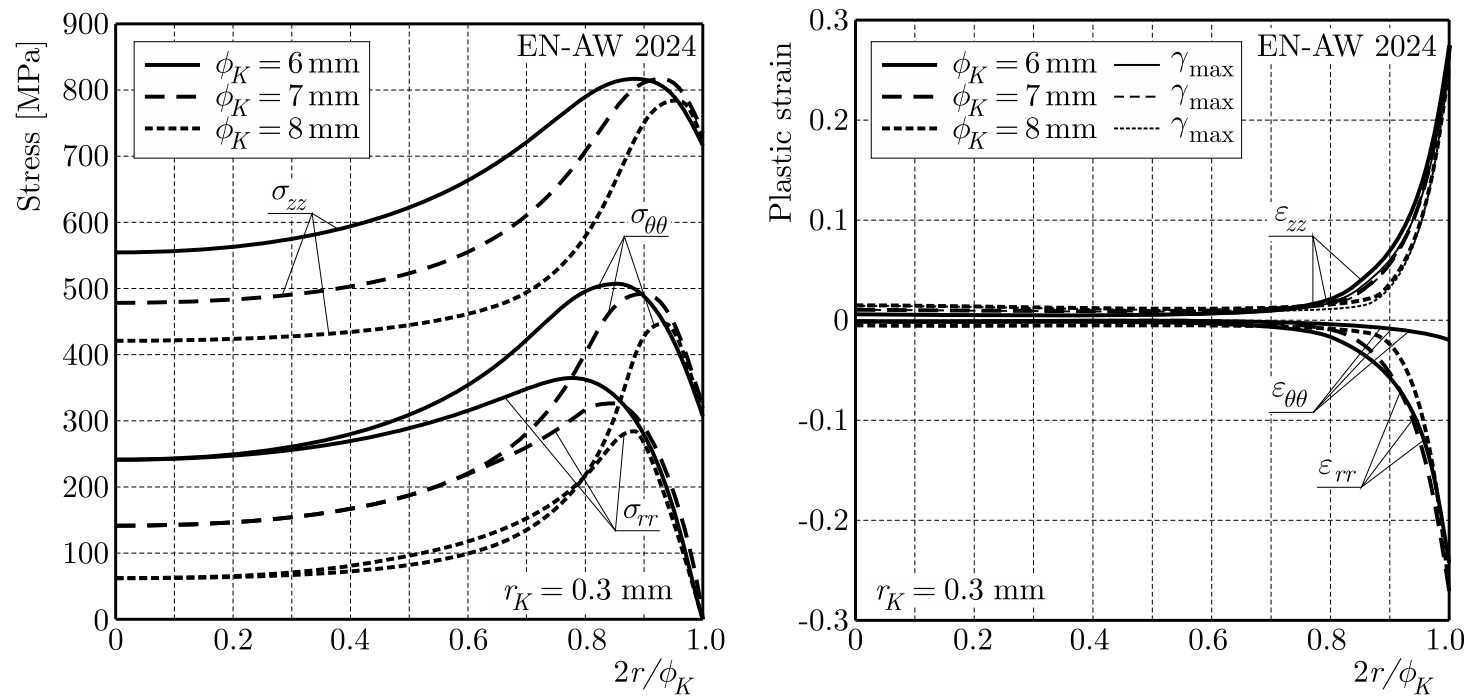

Fig. 7. The distribution of stress and plastic strains in the symmetry plane of the notch at the moment of fracture initiation $\left(r_{k}=0.3 \mathrm{~mm}\right.$, aluminum alloy EN-AW 2024)

\section{Verification of the ductile fracture criterion}

In the literature, there are many papers on ductile fracture criteria for elements with notches. Among them, a certain group stands out, e.g., papers by Wierzbicki et al. (2005), Venugopal et al. (2003), Ozturk and Lee (2004), Han and Kim (2003) developed on the basis of the results of experimental research and numerical calculations and, most often, used in engineering practice. These criteria are described with the help of the scalar function

$$
\int_{0}^{\varepsilon_{f}} f(\boldsymbol{\sigma}) d \varepsilon_{e q}=C
$$

where $\sigma_{e q}$ is the equivalence strain, $\varepsilon_{f}$ - equivalence strain at the moment of fracture initiation, $\boldsymbol{\sigma}$ - stress tensor, $C$ - material constant. The stress function $f(\boldsymbol{\sigma})$ is proposed as various interdependencies between the components of the stress tensor, hydrostatistic stress, maximum and equivalence stress. The constant $C$ plays a role similar to the damage state variable in the 
Table 4. Stress and plastic strain tensor components in tensile specimens with notches at the moment of fracture initiation (aluminum alloy EN-AW 2024)

\begin{tabular}{|c|c|c|c|c|c|c|c|c|c|c|c|c|c|c|c|}
\hline \multirow{2}{*}{$\begin{array}{c}r_{k} \\
{[\mathrm{~mm}]}\end{array}$} & \multirow{2}{*}{$\begin{array}{c}\phi_{k} \\
{[\mathrm{~mm}]}\end{array}$} & \multicolumn{8}{|c|}{ Plastic strain } & \multicolumn{6}{|c|}{ Stress [MPa] } \\
\hline & & \multicolumn{2}{|c|}{$\varepsilon_{r r}$} & \multicolumn{2}{|c|}{$\varepsilon_{\theta \theta}$} & \multicolumn{2}{|c|}{$\varepsilon_{z z}$} & \multicolumn{2}{|c|}{$\gamma_{\max }$} & \multicolumn{2}{|c|}{$\sigma_{r r}$} & \multicolumn{2}{|c|}{$\sigma_{\theta \theta}$} & \multicolumn{2}{|c|}{$\sigma_{z z}$} \\
\hline \multirow{3}{*}{0.3} & 6 & -0.232 & -0.048 & -0.019 & -0.008 & 0.251 & 0.056 & 0.242 & 0.052 & 1.05 & 302.96 & 304.56 & 500.01 & 713.70 & 816.73 \\
\hline & 7 & -0.267 & -0.083 & -0.020 & -0.011 & 0.287 & 0.093 & 0.277 & 0.088 & 1.23 & 241.35 & 319.49 & 477.04 & 731.62 & 817.56 \\
\hline & 8 & -0.243 & -0.075 & -0.019 & -0.012 & 0.262 & 0.087 & 0.252 & 0.081 & 1.29 & 220.31 & 315.06 & 445.79 & 720.85 & 785.79 \\
\hline \multirow{3}{*}{0.5} & 6 & -0.234 & -0.064 & -0.034 & -0.016 & 0.268 & 0.080 & 0.251 & 0.072 & 0.74 & 268.24 & 269.98 & 438.59 & 714.84 & 811.63 \\
\hline & 7 & -0.220 & -0.075 & -0.026 & -0.015 & 0.246 & 0.090 & 0.233 & 0.083 & 0.73 & 209.95 & 283.75 & 412.59 & 706.51 & 774.73 \\
\hline & 8 & -0.217 & -0.093 & -0.025 & -0.017 & 0.241 & 0.110 & 0.229 & 0.101 & 0.65 & 158.57 & 287.12 & 379.04 & 704.24 & 750.66 \\
\hline \multirow{3}{*}{1.0} & 6 & -0.207 & -0.061 & -0.063 & -0.034 & 0.271 & 0.095 & 0.239 & 0.078 & 0.38 & 279.20 & 185.96 & 362.62 & 693.01 & 810.76 \\
\hline & 7 & -0.193 & -0.089 & -0.044 & -0.029 & 0.237 & 0.118 & 0.215 & 0.103 & 0.41 & 156.37 & 223.43 & 316.36 & 686.92 & 740.30 \\
\hline & 8 & -0.201 & -0.108 & -0.041 & -0.037 & 0.241 & 0.139 & 0.221 & 0.123 & 0.31 & 110.82 & 236.53 & 296.48 & 692.51 & 721.86 \\
\hline \multirow{3}{*}{2.0} & 6 & -0.159 & -0.062 & -0.093 & -0.062 & 0.252 & 0.124 & 0.206 & 0.093 & 1.25 & 339.74 & 82.49 & 339.88 & 645.60 & 863.13 \\
\hline & 7 & -0.205 & -0.074 & -0.092 & -0.057 & 0.296 & 0.131 & 0.250 & 0.103 & 1.28 & 229.82 & 121.83 & 272.44 & 682.28 & 780.55 \\
\hline & 8 & -0.219 & -0.122 & -0.081 & -0.061 & 0.300 & 0.183 & 0.259 & 0.152 & 1.19 & 106.17 & 153.59 & 215.63 & 694.81 & 724.91 \\
\hline \multirow{3}{*}{4.0} & 6 & -0.112 & -0.096 & -0.103 & -0.096 & 0.215 & 0.192 & 0.163 & 0.144 & 0.97 & 255.75 & 6.92 & 255.82 & 591.30 & 831.11 \\
\hline & 7 & -0.145 & -0.085 & -0.108 & -0.085 & 0.253 & 0.169 & 0.199 & 0.127 & 0.57 & 255.53 & 30.01 & 255.63 & 621.95 & 816.13 \\
\hline & 8 & -0.201 & -0.089 & -0.125 & -0.886 & 0.327 & 0.177 & 0.264 & 0.133 & 0.34 & 233.01 & 41.23 & 233.01 & 656.60 & 799.06 \\
\hline \multirow{3}{*}{8.0} & 6 & -0.130 & -0.133 & -0.115 & -0.133 & 0.245 & 0.267 & 0.187 & 0.200 & 0.31 & 192.84 & -30.48 & 192.84 & 587.27 & 806.14 \\
\hline & 7 & -0.118 & -0.120 & -0.122 & -0.120 & 0.240 & 0.241 & 0.181 & 0.181 & 0.48 & 201.69 & -24.64 & 201.69 & 588.07 & 802.43 \\
\hline & 8 & -0.139 & -0.125 & -0.155 & -0.125 & 0.294 & 0.251 & 0.224 & 0.188 & 0.41 & 216.98 & -24.50 & 216.97 & 613.47 & 822.75 \\
\hline \multirow{3}{*}{15.0} & 6 & -0.132 & -0.164 & -0.155 & -0.164 & 0.287 & 0.328 & 0.221 & 0.246 & 0.61 & 161.42 & -53.85 & 161.42 & 594.40 & 797.46 \\
\hline & 7 & -0.127 & -0.155 & -0.148 & -0.155 & 0.275 & 0.310 & 0.211 & 0.232 & 0.36 & 164.63 & -46.63 & 164.58 & 592.92 & 795.86 \\
\hline & 8 & -0.132 & -0.147 & -0.145 & -0.147 & 0.277 & 0.294 & 0.211 & 0.221 & 0.45 & 170.65 & -47.75 & 170.64 & 593.20 & 796.51 \\
\hline \multirow{3}{*}{30.0} & 6 & -0.143 & -0.181 & -0.169 & -0.181 & 0.312 & 0.362 & 0.241 & 0.272 & 0.10 & 138.06 & -73.36 & 138.19 & 592.25 & 783.08 \\
\hline & 7 & -0.141 & -0.178 & -0.167 & -0.178 & 0.308 & 0.357 & 0.237 & 0.268 & 0.20 & 143.42 & -70.21 & 143.09 & 592.87 & 786.91 \\
\hline & 8 & -0.140 & -0.175 & -0.164 & -0.175 & 0.304 & 0.350 & 0.234 & 0.263 & 0.09 & 147.06 & -67.80 & 147.05 & 593.10 & 789.14 \\
\hline
\end{tabular}

white box - at the notch root, grey box - at the point of maximum normal stress 

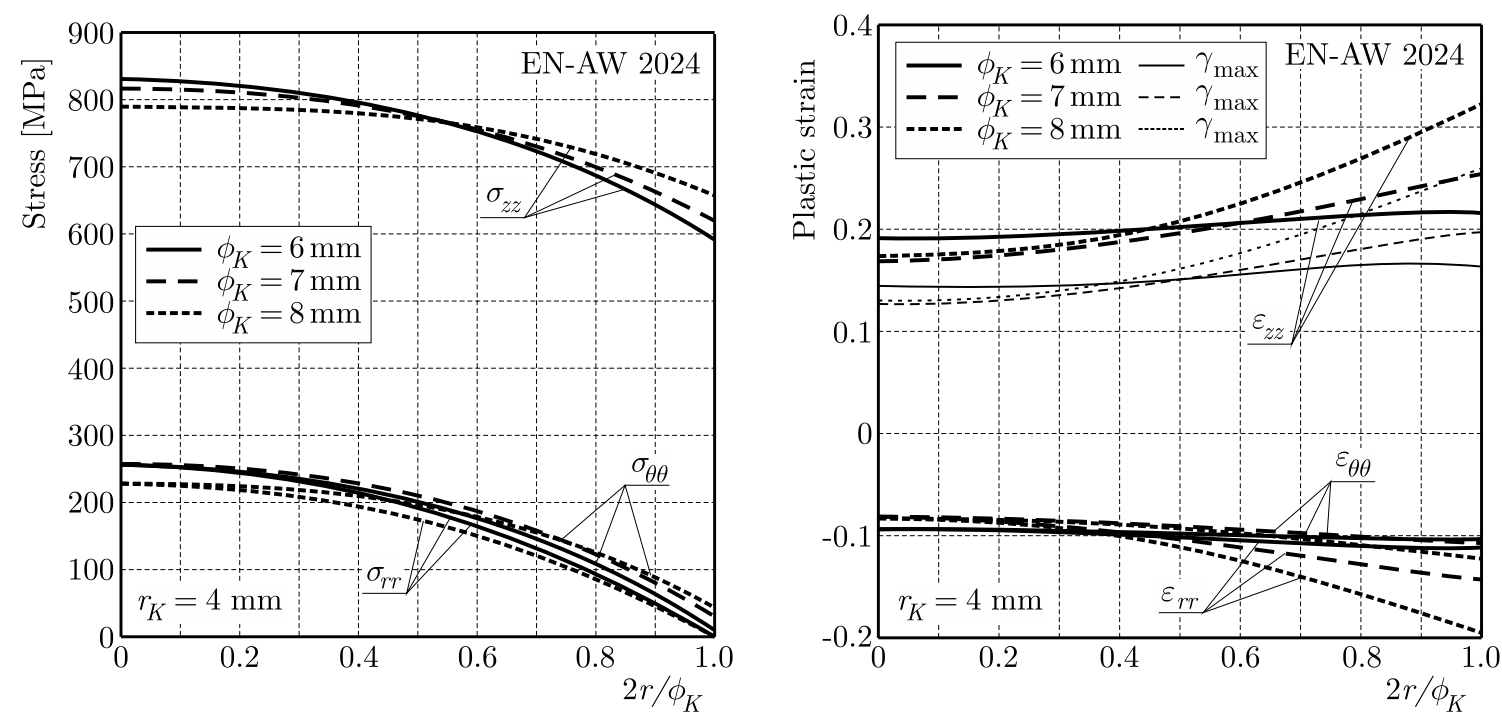

Fig. 8. The distribution of stress and plastic strains in the symmetry plane of the notch at the moment of fracture initiation $\left(r_{k}=4 \mathrm{~mm}\right.$, aluminum alloy EN-AW 2024)
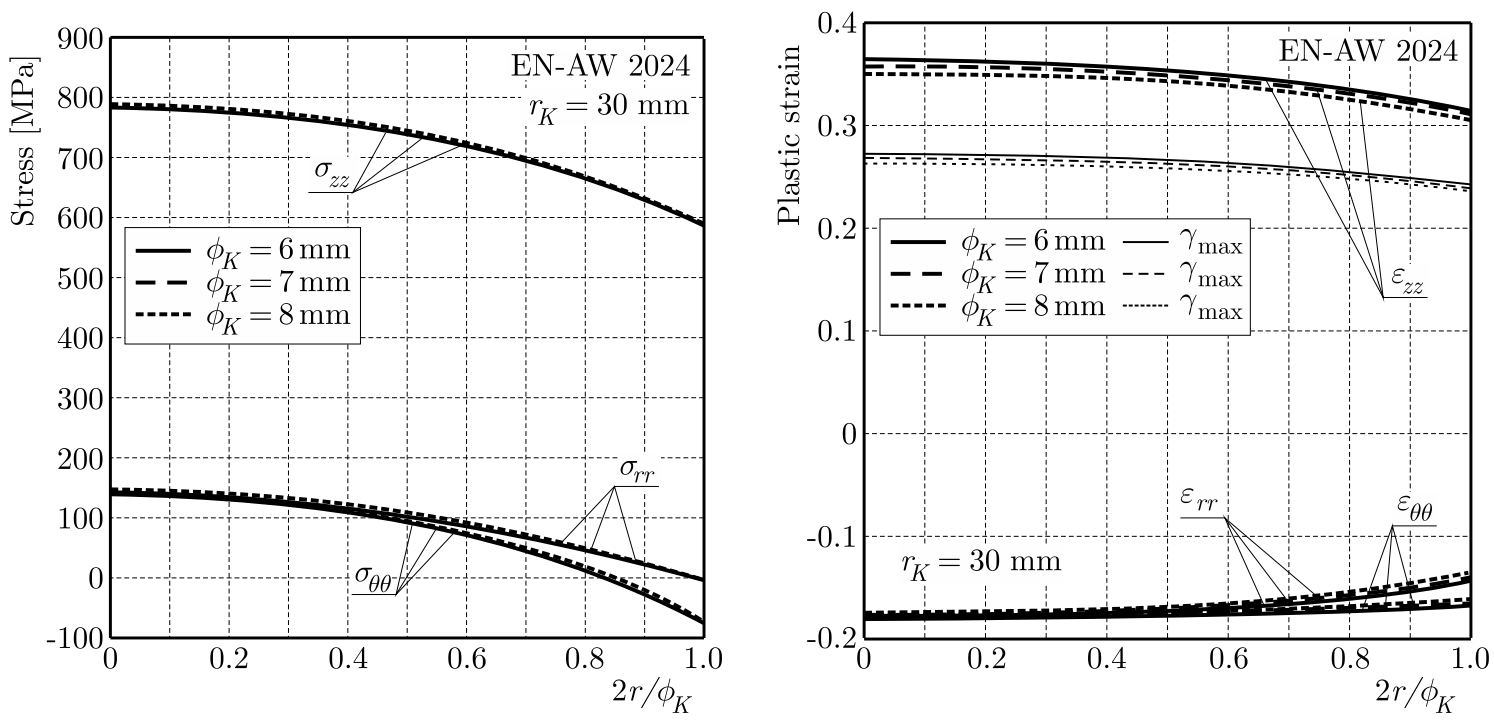

Fig. 9. The distribution of stress and plastic strains in the symmetry plane of the notch at the moment of fracture initiation $\left(r_{k}=30 \mathrm{~mm}\right.$, aluminum alloy EN-AW 2024)

damage mechanics. Our own results from experimental tests (Derpeński and Seweryn, 2011) and numerical calculations of stress and strain fields (Derpeński and Seweryn, 2013) are used for the verification. The most popular criteria (Derpeński and Seweryn, 2008) do not include the material constant in the integrand function. The verification provides the following ductile fracture criteria:

- Cockroft-Latham (1968)

$$
\int_{0}^{\varepsilon_{f}} \sigma_{\max } d \varepsilon_{e q}=C
$$

— hydrostatic stress (McClintock, 1968)

$$
\int_{0}^{\varepsilon_{f}} \frac{\sigma_{H}}{\sigma_{e q}} d \varepsilon_{e q}=C
$$


- Oh et al. (1979)

$$
\int_{0}^{\varepsilon_{f}} \frac{\sigma_{\max }}{\sigma_{e q}} d \varepsilon_{e q}=C
$$

- Brozzo et al. (1972)

$$
\int_{0}^{\varepsilon_{f}} \frac{2 \sigma_{\max }}{3\left(\sigma_{\max }-\sigma_{H}\right)} d \varepsilon_{e q}=C
$$

— Rice-Tracey (1969)

$$
\int_{0}^{\varepsilon_{f}} \exp \left(\frac{3}{2} \frac{\sigma_{H}}{\sigma_{e q}}\right) d \varepsilon_{e q}=C
$$

— Le Roy et al. (1981)

$$
\int_{0}^{\varepsilon_{f}}\left(\sigma_{\max }-\sigma_{H}\right) d \varepsilon_{e q}=C
$$

where $\sigma_{e q}$ is the equivalence stress (in the Huber-von Mises sense), $\sigma_{\max }$ - maximum normal stress, $\sigma_{H}$ - hydrostatistic stress, $\varepsilon_{e q}$ - equivalence strains (in the Huber-von Mises sense).

Authors' own numerical calculations (Derpeński and Seweryn, 2013) show that at the moment of the critical load, the maximum equivalence strain $\varepsilon_{f}$ and maximum stress $\sigma_{\max }$, depending on the shape of the notch, appear in two places:

- $\varepsilon_{f}$ - at the axis of the specimen $\left(r_{k}=8,15,30 \mathrm{~mm}\right)$ and at the notch root $\left(r_{k}=0.3,0.5\right.$, $1,2,4 \mathrm{~mm})$,

- $\sigma_{\max }$ - near the notch root $\left(r_{k}=0.3,0.5,1 \mathrm{~mm}\right)$ and at the axis of the specimen $\left(r_{k}=2\right.$, $4,8,15,30 \mathrm{~mm})$.

Therefore, numerical calculations for these six criteria have been performed at the point where the maximum stress values $\sigma_{\max }$ appeared (in the plane of notch symmetry) and at the notch root. The values of function $f(\boldsymbol{\sigma})$ and equivalent strain for increasing displacement of the measurement base $\Delta u$ have been calculated. Then, on the basis on each criterion, the value of $C$ coefficient has benn calculated. As a result, two values of $C$ coefficient for the assumed material, and type of the notch (at the notch root and at the point of maximal normal stress) have been obtained. The calculation results for the aluminum alloy EN AW 2024 are shown graphically in Fig. 10.

For each of the selected criteria (for specimens with different values of the notch radius $r_{k}$ and the diameter at the notch root $\phi_{k}$ ), the average value of the critical coefficient $C$ and the relative standard deviation $s / \bar{C}$ for these results have been determined. They are presented in Table 5 .

The verification of ductile fracture criteria known from the literature shows large discrepancy between the results of the calculations and experimental data, namely:

- Standard deviation $s$, in reference to the average critical value of coefficient $\bar{C}$, ranges from $10 \%$ to $17 \%$;

- The maximum error for prediction of the fracture of specimens with notches fluctuates from $18 \%$ to $43 \%$; 
(a)

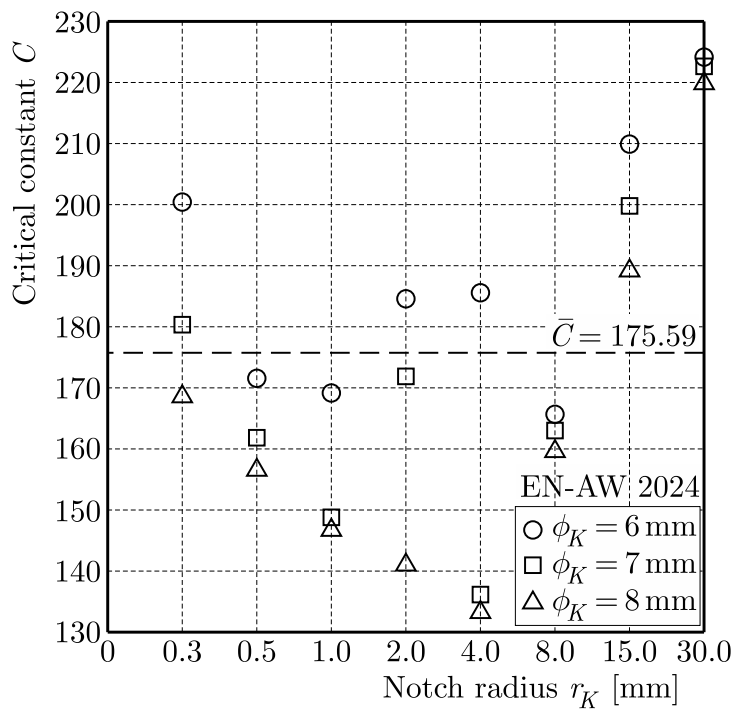

(c)

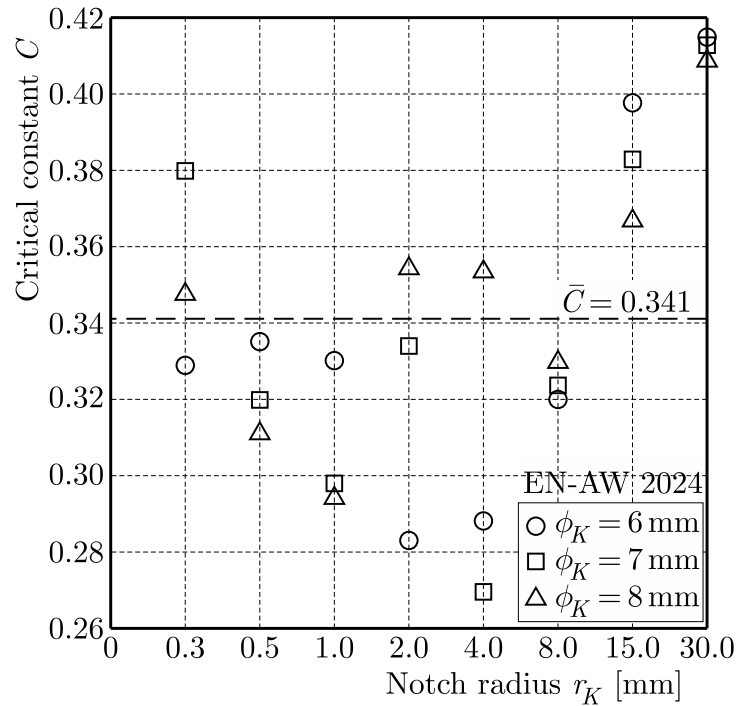

(e)

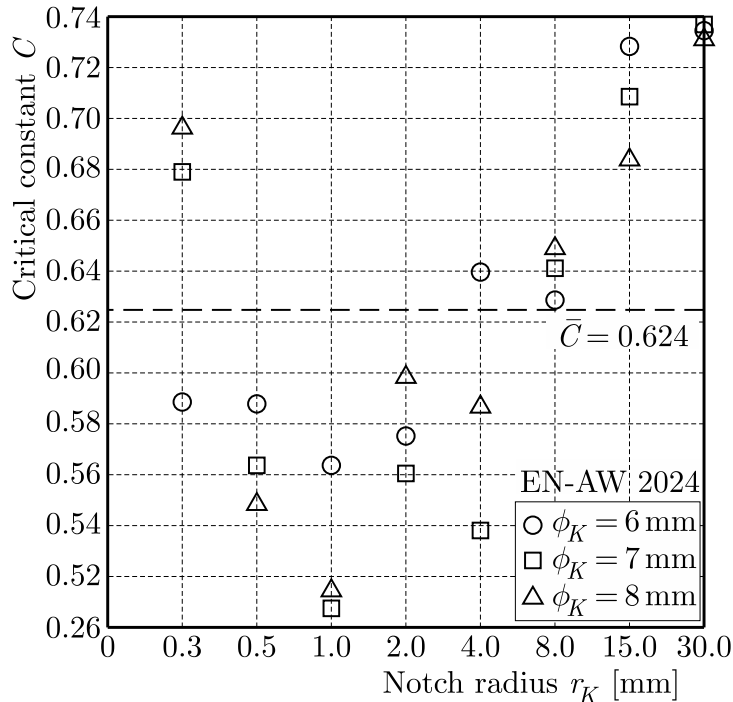

(b)

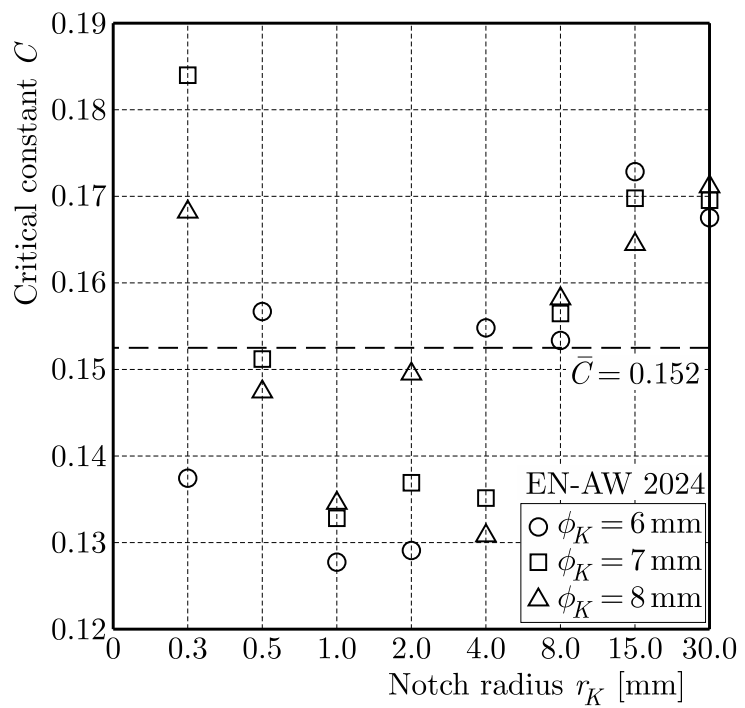

(d)

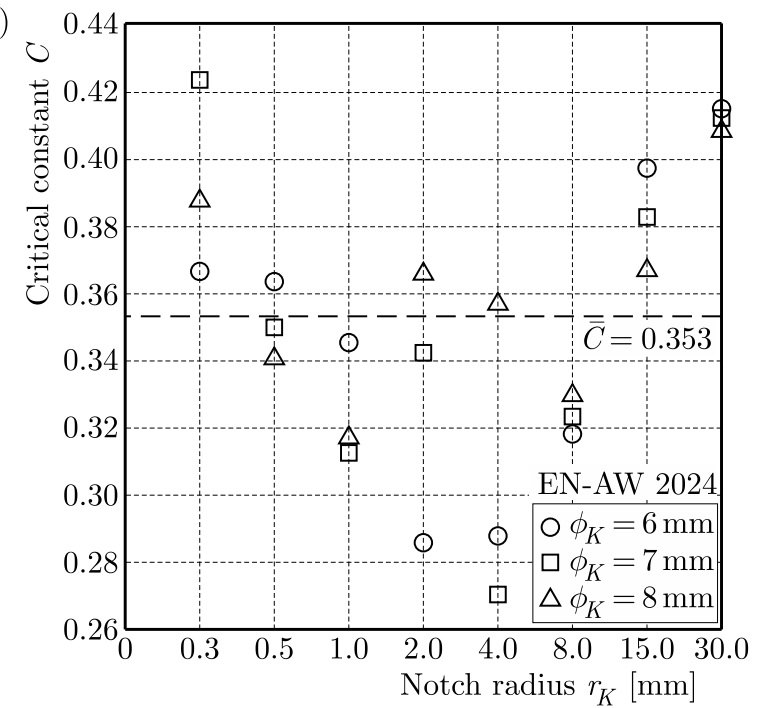

(f)

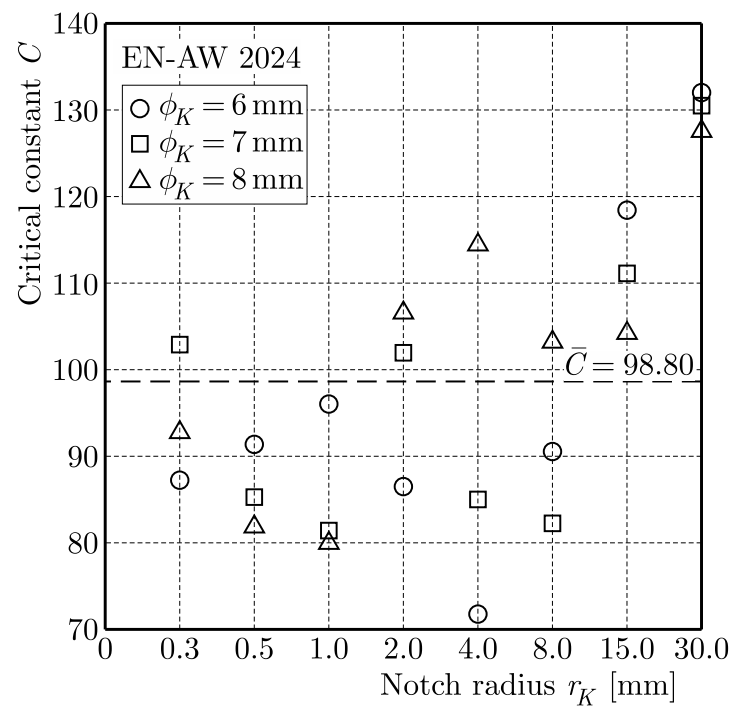

Fig. 10. Results obtained from: Cockcroft-Latham (a), McClintock (b), Oh et al. (c), Brozzo et al. (d), Rice-Tracey (e), LeRoy et al. (f) criterion 
Table 5. Critical values of coefficient $C$

\begin{tabular}{|c|c|c|c|c|}
\hline \multirow{2}{*}{ Criterion } & \multicolumn{4}{|c|}{ EN-AW 2024} \\
\hline & $\bar{C}$ & $s / \bar{C}$ & $1-\left(C_{\min } / \bar{C}\right)$ & $\left(C_{\max } / \bar{C}\right)-1$ \\
\hline "Cockroft-Latham, Eq. (4.2) & 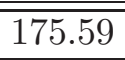 & 0.153 & $\overline{0.236}$ & $\overline{0.276}$ \\
\hline McClintock, Eq. (4.3) & 0.152 & 0.105 & 0.434 & 0.191 \\
\hline Oh et al., Eq. (4.4) & 0.341 & 0.123 & 0.211 & 0.214 \\
\hline Brozzo et al., Eq. (4.5) & 0.353 & 0.122 & 0.357 & 0.184 \\
\hline Rice-Tracey, Eq. (4.6) & 0.624 & 0.119 & 0.178 & 0.178 \\
\hline LeRoy et al., Eq. (4.7) & 98.80 & 0.172 & 0.182 & 0.340 \\
\hline $\begin{array}{l}C_{\min }-\text { minimum value of } \\
C_{\max }-\text { maximum value of } \\
\bar{C}-\text { average value of coeffici }\end{array}$ & $\begin{array}{l}\text { ficient } \\
\text { fficient } \\
C\end{array}$ & & & \\
\hline
\end{tabular}

- With the two parameters defining the shape of the notch in the specimen, the notch radius $r_{k}$ has larger influence on the dispersion of critical values of the coefficient $C$ than the diameter at the notch root $\phi_{k}$.

Therefore, the use of these ductile fracture criteria in practical engineering calculations requires extreme caution and should be limited to special cases documented experimentally.

\section{New ductile fracture criteria for specimens with notches}

The experimental verification of the selected ductile fracture criteria shows that they are not very precise in predicting fracture of aluminum alloys in which there are stress concentrators in form of notches of different shape. Therefore, the authors' own experimental research results and numerical modelling have been used to develop a new fracture criterion.

In the case when the fracture initiation occurs at the axis of symmetry of the specimen (specimens with notch radii $r_{k}>2 \mathrm{~mm}$ ), the fracture plane is perpendicular to the direction of loading. In this plane, large normal stress values appear, which determine the fracture. In the proposed fracture criteria for specimens with notches, it is assumed that the fracture initiation appears when normal stress in this physical plane reaches critical values, depending on the isotropic damage state variable $\omega$ due to plastic flow of the material, namely

$$
\max _{\left(x_{0}\right)} \sigma_{\max }=\sigma_{c}(1-\omega)
$$

where $\sigma_{c}$ is the critical stress for an undamaged material, $\mathbf{x}_{0}$-position vector which determines location of the fracture initiation.

The isotropic damage state variable $\omega$ in the proposed criterion, in the case of monotonic loads, depends on the value of the maximum plastic shear strain $\gamma_{\max }^{p}$

$$
\omega=\frac{\left|\gamma_{\max }^{p}\right|}{\gamma_{c}^{p}}
$$

where $\gamma_{c}^{p}$ is the critical plastic shear strain.

Figure 11 shows a comparison of the critical stress $\sigma_{\max }$ in function of the maximum plastic shear strain $\left|\gamma_{\max }^{p}\right|$ obtained on the basis of dependences (5.1) and (5.2) and experimental research. Into consideration are only taken the specimens with notches for which $\sigma_{\max }$ and $\left|\gamma_{\max }^{p}\right|$ occur on the axis of symmetry of the specimen. These are the specimens with dimensions:

$-r_{k}=2 \mathrm{~mm} ; \phi_{k}=6 \mathrm{~mm}$ 
$-r_{k}=4,8,15,30 \mathrm{~mm} ; \phi_{k}=6,7,8 \mathrm{~mm}$

— without notch (smooth).

In the case of the examined aluminum alloy, the following critical values have been determined: $\sigma_{c}=876.5 \mathrm{MPa}, \gamma_{c}^{p}=2.42$.

In figures below, the following indicators of points obtained from the experimental research and numerical analysis are used: the first number shows $r_{k}$, and the second (after the dash) shows $\phi_{k}$. In the figures, the places of points outermost from the line defining the proposed ductile fracture criterion are marked by the dashed line.

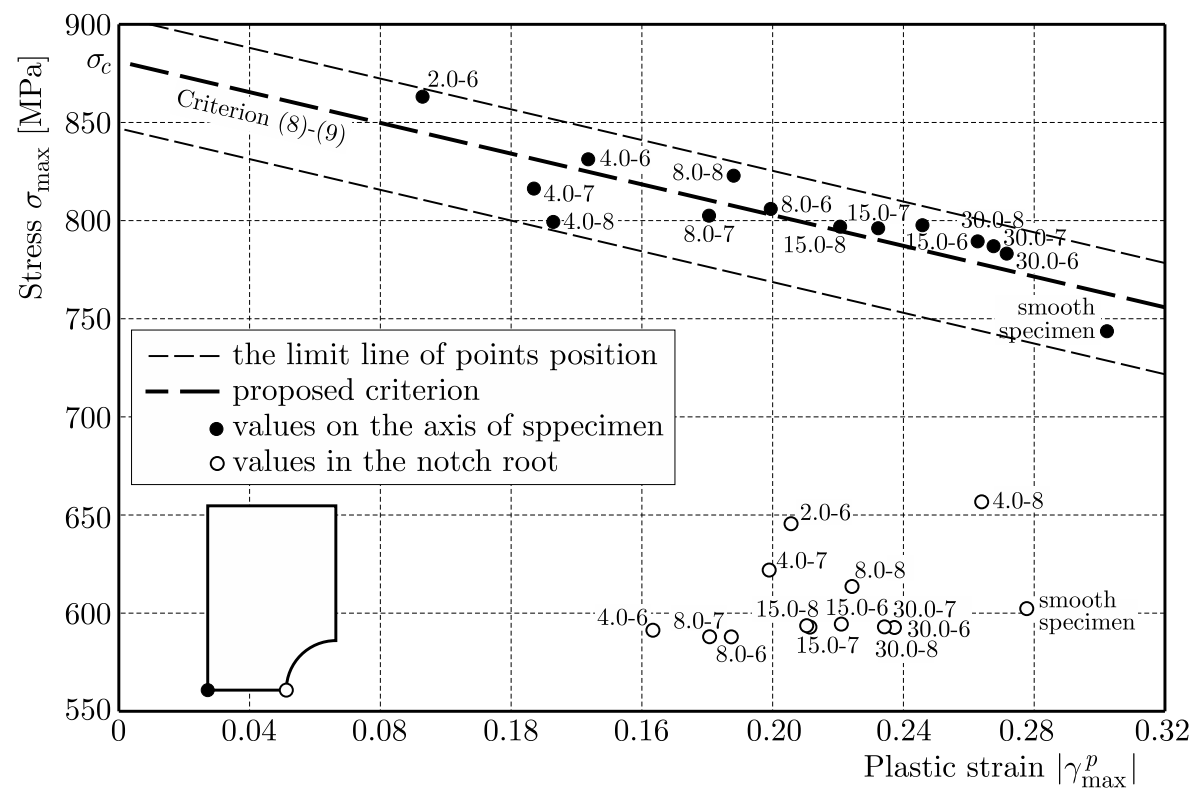

Fig. 11. Dependence of the critical normal stress on the maximum plastic shear strain. Fracture at the axis of the specimen

Another situation is faced in the case of specimens with small radii of notches. It is important to investigate two potential places for fracture initiation:

- the notch root, where the maximum plastic transverse strain appears,

- the point at a certain distance from the notch root, where there is maximum normal stress value.

In both cases, the fracture plane is perpendicular in the direction of the load and is covered by the plane of symmetry of the notch. Figure 12 shows the normal stress $\sigma_{\max }$ and the maximal plastic shear strains $\gamma_{\max }^{p}$ in both the above-mentioned points for the specimens with small notch radii. It is important to note that all values lie significantly below the line marking fracture condition (5.1) and (5.2) (Fig. 11). It can therefore be concluded that the state of damage inside the material is different than in a thin layer near the free surface. It is assumed that the machining process, which has been used for blanking the notches, has made the initial damage to the material. In the course, for example, of machining in the vicinity of the tool tip, a plastic zone through which the fracture surface passes (separation surface of a material) occurs. In this zone, large plastic strains appear, similar to those in the plastic zone ahead the crack tip. The part of this zone remains during the machining, hence also, in some thin layer in the vicinity of the free surface the plastic strain remains, and so the associated to them preliminary damage of the material. This is also why, in the case of the free surface, it is necessary to modify formula (5.2) in the following way

$$
\omega=\frac{\left|\gamma_{\max }^{p}\right|}{\gamma_{c}^{p}}+\omega_{0}
$$


where $\omega_{0}$ is the preliminary damage of the material on the free surface resulting from the manufacturing process.

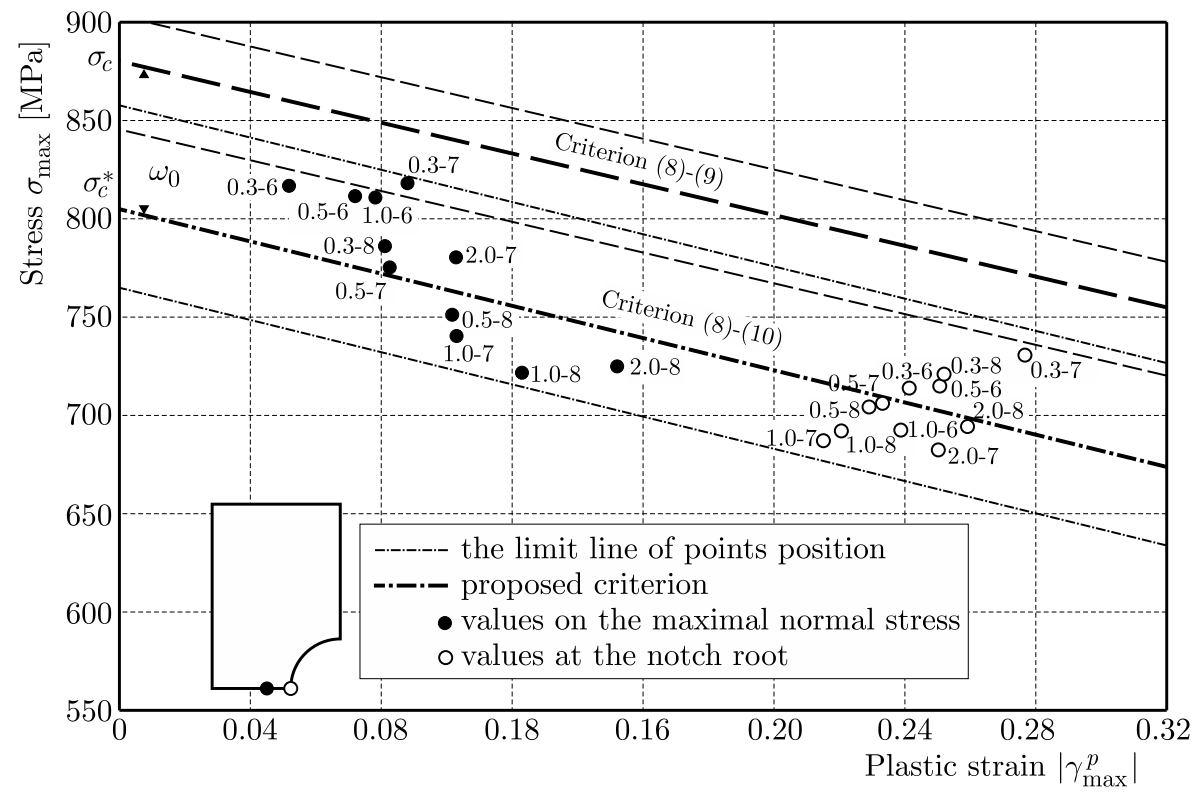

Fig. 12. Dependence of the critical normal stress on the maximum plastic shear strain (fracture in the vicinity of the notch root)

Taking into consideration the material damage $\omega_{0}$ on the surface of the notch, one can predict the fracture of the specimens with notches with a small radius $\left(r_{k} \leqslant 2 \mathrm{~mm}\right)$. It is necessary to take into account much larger values for plastic strains (as well as the maximum plastic shear strains $\gamma_{\max }^{p}$ ) for those specimens at the notch root. It can be therefore assumed that the fracture initiation in the specimens with small radii of the notch $r_{k}$ appears at the notch root. Figure 12 shows that the points obtained from the experimental research and numerical analysis for the values of stress and strain at the notch root are close to fracture condition (5.1) and (5.2). For these points, the value of the preliminary material damage $\omega_{0}=0.087$ has been obtained.

The fracture condition on the surface of the notch is fulfilled for all specimens with notches, in which the maximum normal stress and plastic shear strain (at the moment of fracture initiation) are not located on the axis of symmetry. The same situation we have in the case of notches with the following parameters: $r_{k}=0.3 \mathrm{~mm} ; \phi_{k}=67,8 \mathrm{~mm} ; r_{k}=0.5 \mathrm{~mm} ; \phi_{k}=6,7,8 \mathrm{~mm}$; $r_{k}=1 \mathrm{~mm} ; \phi_{k}=6,7,8 \mathrm{~mm} ; r_{k}=2 \mathrm{~mm} ; \phi_{k}=7,8 \mathrm{~mm}$.

\section{Conclusion}

On the basis of the earlier experimental research conducted on specimens with notches made of aluminum alloys EN-AW 2024, it follows that the normal stress vector component on the critical plane determines the fracture. This plane, in the case of tensile specimens with notches, is perpendicular to the load direction. It is assumed that the value of the critical normal stress dependents on the maximal plastic shear strains, assuming that the accumulated damage (and material weakening) occurs faster on the free surface than on the inside of the material. Through the assumptions made, the formula of the proposed fracture criterion is characterized by a simple relationship. It is also important to note that a better correlation of the results of calculations on the basis of the proposed criterion with the experimental research has been obtained than in the case of the verification criteria found in the literature. The mean error for 
fracture prediction of the specimens with notches has been found $1.6 \%$, whereas the maximum error of the modeling $4.6 \%$

Acknowledgement

This work has been financially supported by National Science Centre (Poland) under the project DEC-2011/03/B/ST8/06456.

\section{References}

1. Bandsta J.P., Koss D.A., 2004, A simulation of growth and coalescence of void during ductile fracture, Materials Science and Engineering, 387, 399-403

2. BaO Y., 2001, Comparative Study on Various Fracture Criteria. Part II: Finite Element Analysis, Cambridge, MIT.P.40

3. BAO Y., 2005, Dependence of ductile crack formation in tensile tests on stress triaxiality, stress and strain ratios, Engineering Fracture Mechanics, 72, 505-522

4. Bringdman P.W., 1964, Studies in Large Plastic Flow and Fracture with Special Emphasis on the Effects of Hydrostatic Pressure, Harvard University Press, Cambridge

5. Brozzo P., De Luka B., Rendina R., 1972, A new method for the prediction of formability in metal sheets, Proceedings of the Seventh Biennial Conference on Sheet Metal Forming and Formability - International Deep Drawing Research Group, 44

6. Chena J., Zhoub X., Chen J., 2015, Sheet metal forming limit prediction based on plastic deformation energy, Journal of Materials Processing Technology, 315-322

7. Cockroft M.G., Latham M.G., 1968, Ductility and the workability of metals, Journal of the Institute of Metals, 98, 33-41

8. Derpeński Ł., Seweryn A., 2008, Verification of selected fracture criteria of elements with notches (in Polish), XXII Symposium Fatigue and Fracture Mechanic

9. Derpeński Ł., Seweryn A., 2011, Experimental research into fracture of EN-AW 2024 and EN-AW 2007 aluminum alloy specimens witch notches subjected to tension, Experimental Mechanics, 51, 1075-1094

10. Derpeński Ł, Seweryn A., 2013, Numerical, Analysis of the Strain and Stress State in Cylindrical Notched Tensile Specimens, Materials Science, 49, 252-256

11. Han H.N., Kim K.H., 2003, A ductile fracture criterion in sheet metal forming process, Journal of Materials Processing Technology, 142, 231-238

12. Komori K., 2005, Ductile fracture criteria for simulating shear by node separation method, Theoretical and Applied Fracture Mechanics, 43, 101-114

13. Le Roy G., Embury J. D., Edward G., Ashby M.F., 1981, A model of ductile fracture based on the nucleation and growth of voids, Acta Metallurgica, 29, 1509-1522

14. Ma H., Xu W., Jin B.C., Shan D., Nutt S.R., 2015, Damage evaluation in tube spinnability test with ductile fracture criteria, International Journal of Mechanical Sciences, 100, 99-111

15. McClintock F.A., 1968, A criterion for ductile fracture by the growth of holes, Journal of Applied Mechanics, 35, 353-371

16. Öchsner A., Gegner J., Winter W., Kuhh G., 2001, Experimental and numerical investigations of ductile damage in aluminum alloy, Materials Science and Engineering, A318, 328-333

17. Oh S.I, Chen C.C., Kobayashi S., 1979, Ductile fracture in axisymmetric extrusion and drawing, Journal of Engineering for Industry, Transactions of the ASME, 101

18. Ozturk F., Lee D., 2004, Analysis of forming limits using ductile fracture criteria, Journal of Materials Processing Technology, 147, 397-404 
19. Rice J.R, Tracey D.M., 1969, On the ductile enlargement of voids in triaxial stress fields, Journal of the Mechanics and Physics of Solids, 17, 201-217

20. Thomason P.F., 1990, Ductile Fracture of Metals, NY, Pergamon Press

21. Venugopal R., Ramakrishnan N., Krishna Kumar R., 2003, A comparative evaluation of the theoretical failure criteria for workability in cold forging, Journal of Materials Processing Technology, 142, 29-42

22. Yanshan L., Hoon H., 2013, Evaluation of ductile fracturecriteria in ageneral three-dimensional stress state considering the stress triaxiality and the Lode parameter, Acta Mechanica Solida Sinica, 26, 6

23. Yanshan L., Hoon H., Sunguun L., Keunhwan P., 2012, New ductile fracture criterion for prediction of fracture forming limit diagrams of sheet metals, International Journal of Solids and Structures, 49, 3605-3615

24. WierzBicki T., BAo Y., Lee Y.W., BAi Y., 2005, Calibration and evaluation of fracture models, International Journal of Mechanical Sciences at Science, 47, 719-743

Manuscript received July 17, 2015; accepted for print December 29, 2015 